\title{
Surgical treatment of dislocations of the acromioclavicular joint in the athlete
}

\author{
M. Krueger-Franke MD, C. H. Siebert MD* and B. Rosemeyer MD \\ Staatliche Orthopaedische Klinik Muenchen, Munich, Germany and *Klinik für Unfallchirurgie, Bonn, Germany
}

The treatment of the sports related dislocation of the acromioclavicular joint remains controversial. This study was carried out to determine whether or not a combined surgical procedure consisting of repair and polydioxanone (PDS)-cord augmentation of the coracoclavicular ligaments, fixation of the acromioclavicular joint with a single Kirschner wire as well as the repair of the acromioclavicular ligament permitted return to athletic activity. Athletes were examined with regard to their range of motion, pain and their ability to return to the performance level achieved before the injury. During the period 1986-1989, 21 athletes were treated. Follow-up averaged 22 months. Return of athletes to previous performance level was related to their original degree of activity. Two recreational once-a-week athletes did not return to this level, 19 patients, including five competitive athletes, continued their previous activities. There was no correlation between coracoclavicular ossification or posttraumatic arthritis and a good or excellent result. We recommend the operative treatment of acromioclavicular separations in athletes.

Keywords: Acromioclavicular separation, dislocation of the acromioclavicular joint, PDS-cord, ligament augmentation, sports injury, transarticular wire fixation

The dislocation of the acromioclavicular joint is a common injury seen in athletes ${ }^{1-3}$ and in bicyclists involved in road accidents ${ }^{4,5}$. For a long time, these injuries were treated conservatively ${ }^{6}$. Since the introduction of the Bosworth procedure in $1941^{7}$, surgery has become popular. Recently a combined approach with many different methods and implants has been described ${ }^{8-10}$.

The management of the injury is dependent on the classification of the dislocation of the acromioclavicular joint as described by Tossy in $1963^{11}$ :

Grade 1. Sprain of the acromioclavicular joint without ligament injury or instability; treated conservatively.

Grade 2. Disruption of the acromioclavicular joint with tear of the acromioclavicular ligament and

Address for correspondence: Dr M. Krueger-Franke, Staatliche Orthopaedische Klinik Muenchen, Harlachinger Strasse 51, D-8000 Muenchen 90, Germany

(C) 1993 Butterworth-Heinemann Ltd 0306-3674/93/020121-04

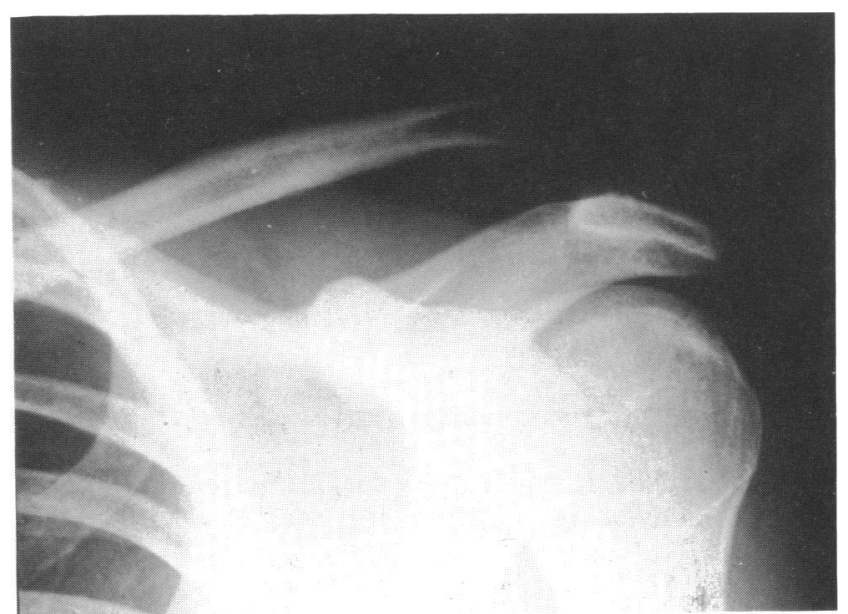

Figure 1. Grade 3 injury of the left acromioclavicular joint in a 47-year-old skier

upward displacement of the clavicle of up to half the shaft thickness; this injury is also generally treated conservatively, 11,12 .

Grade 3. Complete disruption of the acromioclavicular joint with tear of the acromioclavicular and coracoclavicular ligaments and dislocation of the clavicle by more than half of the shaft-thickness (Figure 1). This type of injury should be managed surgically, 10,11,13. A multitude of surgical procedures have been described and can be divided according to three principles ${ }^{10}$ : direct procedure with sole repair of the acromioclavicular joint and its ligaments; indirect procedure with sole repair of the coracoclavicular ligaments; combined procedures.

The goal must be to restore the joint space and obtain a good functional result ${ }^{14}$, with pain free loading of the joint ${ }^{1}$.

\section{Patients and methods}

During the period from 1 September 1986 to 30 June 1989 , of 35 patients (33 men, two women) surgically treated for Tossy grade 3 injuries at the Staatliche Orthopaedische Klinik in Munich 23 had sports related injuries (Figure 2). 


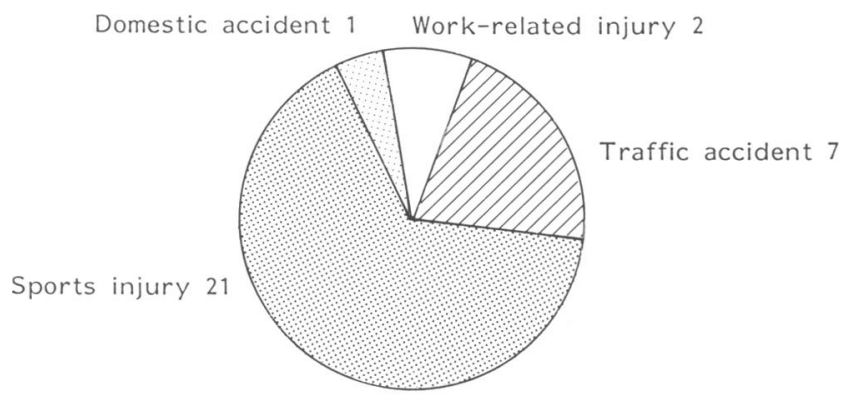

Causes of injury $(n=35)$

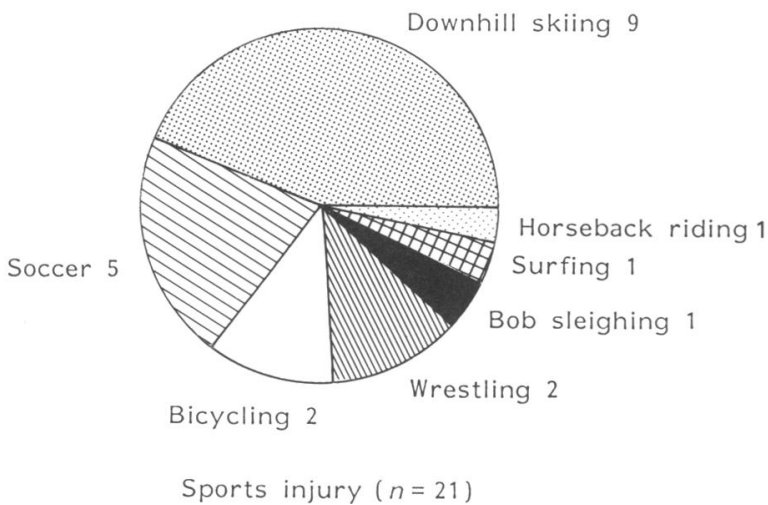

Figure 2. Causes of injury in 35 surgically treated patients and the activity responsible for the 21 sport-related injuries

\section{Operative technique}

A sabre-cut approach is used to expose the acromioclavicular joint and the coracoclavicular ligaments. Sutures are placed in the ruptured coracoclavicular ligaments, but not tied, and a PDS-cord (thickness $1.5 \mathrm{~mm}$ ) is passed around the coracoid process and the clavicle. The articular disc is then inspected and debrided or reattached. The dislocation is reduced and a single $2.0 \mathrm{~mm}$-thick unthreaded Kirschner wire inserted into the acromion and advanced into the clavicle. The position and reduction are then checked.

The capsule and acromioclavicular ligament are repaired and the sutures in the coracoclavicular ligaments and the PDS-cord tied. A suction drain is introduced and the wound is closed layer for layer.

After operation, a Velpeau dressing or sling-and00 an abduction cast for 6 weeks after operation. The Kirschner wire is then removed under local anaesthesia. Physical therapy and active motion are then begun.

\section{Follow-up examination}

Twenty-one patients were examined, on average, 22 months after operation. The mean (range) was 40 (23-73) years. There were 20 men and one woman. One patient refused radiography.

The patients completed a questionnaire that related mainly to the quality and quantity of their sports activity before and after injury.
Table 1. Criteria for the clinical follow-up examination and the assigned points for the rating system ${ }^{15}$

\begin{tabular}{|c|c|}
\hline Clinical criteria & Points \\
\hline $\begin{array}{l}\text { Acromioclavicular joi } \\
\text { Present } \\
\text { Not present }\end{array}$ & $\begin{array}{l}2 \\
0\end{array}$ \\
\hline $\begin{array}{l}\text { Muscle atrophy } \\
\text { Present } \\
\text { Not present }\end{array}$ & $\begin{array}{l}1 \\
0\end{array}$ \\
\hline $\begin{array}{l}\text { 'Floating' distal clavic } \\
\text { None } \\
\text { Minimal } \\
\text { Moderate } \\
\text { Marked }\end{array}$ & $\begin{array}{l}3 \\
2 \\
1 \\
0\end{array}$ \\
\hline $\begin{array}{l}\text { Pressure sensitive po } \\
\text { None } \\
1 \\
2 \\
3 \text { and more }\end{array}$ & $\begin{array}{l}3 \\
2 \\
1 \\
0\end{array}$ \\
\hline $\begin{array}{l}\text { Shoulder function } \\
\text { Free active ROM } \\
\text { Restriction }>20^{\circ} \\
\text { Free passive ROM } \\
\text { Restriction }>20^{\circ}\end{array}$ & $\begin{array}{l}2 \\
0 \\
2 \\
0\end{array}$ \\
\hline $\begin{array}{l}\text { Painful arc } \\
\text { Present } \\
\text { Not present }\end{array}$ & $\begin{array}{l}3 \\
0\end{array}$ \\
\hline $\begin{array}{l}\text { Starter pain } \\
\text { Present } \\
\text { Not present }\end{array}$ & $\begin{array}{l}1 \\
0\end{array}$ \\
\hline $\begin{array}{l}\text { 'Scratch test' - neck } \\
\text { Negative } \\
\text { Positive/painful }\end{array}$ & $\begin{array}{l}1 \\
0\end{array}$ \\
\hline $\begin{array}{l}\text { 'Scratch test' - back } \\
\text { Negative } \\
\text { Positive/painful }\end{array}$ & $\begin{array}{l}1 \\
0\end{array}$ \\
\hline $\begin{array}{l}\text { Apprehension test } \\
\text { Negative } \\
\text { Positive/painful }\end{array}$ & $\begin{array}{l}1 \\
0\end{array}$ \\
\hline
\end{tabular}

*Points were allocated to the various clinical findings to permit classification of the results; ROM, range of movements

The results of the clinical examination were documented (Table 1). The examination included an anteroposterior radiograph of both shoulders while supporting a weight of $10 \mathrm{~kg}$ to evaluate the joint position, and assess post-traumatic arthritis and ossification of the coracoclavicular ligaments (Figure 3 and Table 2).

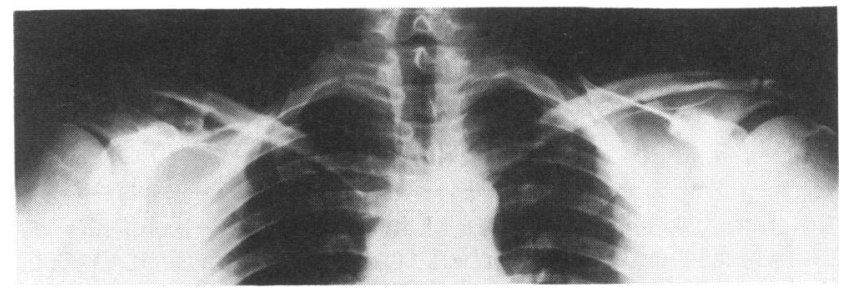

Figure 3. Coracoclavicular ossification in a 35-year-old soccer player following an operatively treated grade 3 lesion. Excellent overall result 
Table 2. Criteria for the radiological follow-up examination and the points assigned ${ }^{15}$

\begin{tabular}{lc}
\hline Radiological criteria & Points* \\
\hline Dislocation of the clavicle & \\
Less than half of shaft thickness & 6 \\
Half total shaft thickness & 3 \\
More than shaft thickness & 0 \\
Coracoclavicular interspace compared with opposite shoulder \\
$0-5$ mm difference & 6 \\
$5-10 \mathrm{~mm}$ difference & 3 \\
>10 mm difference & 0 \\
Post-traumatic arthritis & \\
None & 5 \\
Minimal & 4 \\
Moderate & 2 \\
Marked & 0 \\
Coracoclavicular ossification & \\
None & 3 \\
Minimal & 2 \\
Moderate & 1 \\
Massive & 0 \\
\hline
\end{tabular}

*Points were allocated to the various radiological findings to permit classification of the results

\section{Results}

Of the acromioclavicular separations, $43 \%$ resulted from injury during alpine skiing. In 20 instances there was a fall on the involved shoulder, and in one a fall on the abducted extremity.

Of the 21 athletes, five took part in competitive sports, and 16 were recreational athletes, 11 training three times a week and five participating in sport once a week. At follow-up all five competitive athletes, the 11 active recreational athletes and three of the five once-a-week recreational athletes had returned to their performance level before operation. The remaining two low-activity athletes gave up sports completely.

The clinical follow-up grade was good or excellent in $90 \%$ of all athletes (Table 3 ).

Some $81 \%$ of the examined patients reported to be pleased or very pleased with the result. Given the same situation, 19 patients would opt for surgical treatment again while two would prefer conservative management.

The radiographic grading of $70 \%$ was good or excellent (Table 3). Two patients had an upward

Table 3. Distribution of clinical and radiological results as cumulative scores

\begin{tabular}{llrr}
\hline Score (points) & \multicolumn{1}{c}{ Rating } & \multicolumn{2}{c}{ Result } \\
\cline { 3 - 4 } & & Clinical & Radiological \\
& & 18 & 13 \\
$17-20$ & Excellent & 1 & 1 \\
$14-16$ & Good & 2 & 4 \\
$11-13$ & Satisfactory & 0 & 2 \\
$6-10$ & Non-satisfactory & 0 & 0 \\
$0-5$ & Poor & & \\
\hline
\end{tabular}

displacement of the lateral clavicle of $5-10 \mathrm{~mm}$ and one a displacement of greater than $10 \mathrm{~mm}$. Changes of post-traumatic arthritis were seen in 16 and four were graded as moderate or marked. Coracoclavicular ossification was noted in 17 instances (Figure 3).

\section{Discussion}

Dislocation of the acromioclavicular joint is usually caused by the direct trauma of a fall on the affected shoulder ${ }^{16}$. The leading causes of injury are sport forms associated with multiple falls such as the martial arts, bicycling, motorbiking and alpine skiing $^{1-3}$.

In our group, the injuries occurred primarily during alpine skiing (9 cases; $43 \%$ ), which is partly owing to Munich's proximity to the Alps, but also during soccer (5 cases; $24 \%$ ) and usually during tackling and headers.

The patient's ability to return to sport seems to be related to the patient's preinjury activity level. All competitive athletes and the recreational athletes actively participating in sports at least three times a week returned to the previous performance level following surgical treatment. Of the five once-a-week recreational athletes only three returned to the original level. These results are in line with those of $\mathrm{Mayr}^{3}$, who reported that the higher activity level leads to better muscle conditioning and enables the active athletes to recover from surgery and restore function in the affected extremity more easily.

The question of an age limit for the surgical treatment of dislocations of the acromioclavicular joint should be seen in the same context. Larsen ${ }^{17}$ generally recommends conservative management of patients over 45 years of age, due to a high rate of poor results following surgical intervention in this group but in our study, four of the five patients older than 45 years of age were classified as good or excellent, and we have come to the conclusion that surgical management should be considered for the athletically active patient of 45 years and older. A generalized age limit does not seem to be appropriate.

The results show a distinct difference between the clinical and radiological evaluation of the surgically treated athlete, which is comparable to the findings of other authors ${ }^{13,17,18}$. Coracoclavicular ossification or elevation of the lateral clavicle of up to half the shaft thickness does not influence the clinical result ${ }^{18,19}$. In his examination of 35 athletes with non-surgically treated acromioclavicular separations, Glick found that an anatomical reduction was not necessary to obtain a good functional result ${ }^{19}$. This is corroborated by Taft, whose comparison of surgical and nonsurgical treatment of complete acromioclavicular separations (grade 3) in 127 patients revealed an anatomical position in $71 \%$ of the surgically treated patients and in only $9 \%$ of the patients managed conservatively ${ }^{18}$. He also observed a higher rate of post-traumatic arthritis in the non-surgical patient than in the surgically treated individuals ${ }^{18}$, which did not seem to influence the clinical symptoms. His results lead him to recommend the non-surgical treatment of the acromioclavicular separation in a 
Kenny-Howard splint worn over a period of 4 weeks.

Our follow-up study shows that a combined surgical procedure including the repair of the coracoclavicular ligaments with a PDS-cord augmentation and a transarticular wire-fixation, as well as the revision of the acromioclavicular joint leads to good-to-excellent clinical results in $90 \%$ of the examined athletes. The return to the previous level of sporting activity of the conditioned athlete has led us to recommend the surgical treatment of dislocations of the acromioclavicular joint in patients actively involved in sports.

\section{References}

1 Haas N, Blauth M. Verletzungen des Acromio- und Sternoclaviculargelenkes - operative oder konservative Behandlung? Orthopäde 1989; 18: 234-46.

2 Keller HW, Rehm KE. Sportverletzungen der Schulter. Klinikarzt 1990; 19: 189-96.

3 Mayr B. Acromioclavicularsprengung - Ergebnisse der operativen Behandlung. Inaugural Dissertation, München, Germany: Ludwig Maximilians Universität, 1987.

4 Armbrecht A, Grandins J. Die temporäre extraartikuläre Fixation nach Bosworth bei vollständiger Schultereckgelenkssprengung. Aktuel Traumatol 1990; 20: 283-7.

5 Fröhling M, Zichner L. Die Versorgung der Schultereckgelenksluxation nach Bosworth. Sportverletz Sportschaden 1989; 3: 88-91.

6 Urist MR. Complete dislocations of the acromioclavicular joint. J Bone Joint Surg [Am] 1946; 28-A: 813-37.

7 Bosworth BM. Acromioclavicular separation. New method of repair. Surg Gynecol Obstet 1941; 71: 866-81.
8 Moschinski D, Linke R, Drühe V. Operative Behandlung der frischen Schultereckgelenkssprengung mit resorbierbarem Nahtmaterial. Aktuelle Chirurgie 1987; 22: 183-6.

9 Rehm KE, Schultheis KH. Bandersatz mit Polydioxanon (PDS). Unfallchirurgie 1985; 11: 264-73.

10 Rockwood CA. Subluxation and dislocations about the shoulder. In: Rockwood CA, Green DP, eds. Fractures in Adults. Philadelphia, Pennsylvania, USA: Lippincott, 1984: 722.

11 Tossy JD, Mead NC, Sigmond HM. Acromioclavicular separation: useful and practical classification for treatment. Clin Orthop 1963; 28: 111-29.

12 Alste HE van, Lasarzewski B. Alloplastische Versorgung von Schultereckgelenksverletzungen (Tossy III). Sporttraumatologie und Sportmedizin 1989; 2: 15-19.

13 Rustemeier M, Kulenkampff H-A. Die operative Behandlung der Acromioclaviculargelenk-Sprengung mit einer resorbierbaren PDS-Kordel. Unfallchirurgie 1990; 16: 70-4.

14 Park JP, Arnold JA, Coher TP, Harris WD, Becker DA. Treatment of acromioclavicular separations. A retrospective study. Am. J Sports Med 1980; 8: 251-8.

15 Boenisch V, Huyer C, Wasmer G. Standardisierte Schulteruntersuchung unter Berüchsichtigung der computerisierten isokinetischen kraftmessung. Sportverletz Sportschaden 1991; 1: 5-11.

16 Post M. Current concepts in the diagnosis and management of acromioclavicular dislocations. Clin Orthop 1985; 200: 234-47.

17 Larsen E, Bjerg-Nielsen A, Christensen P. Conservative or surgical treatment of acromioclavicular dislocation. J Bone Joint Surg [Am] 1986; 68-A: 552-5.

18 Taft TN, Wilson FC, Oglesby JW. Dislocation of the acromioclavicular joint. An end-result study. J Bone Joint Surg [Am] 1987; 69-A: 1045-51.

19 Glick JM. Dislocated acromioclavicular joint: follow-up study of 35 unreduced acromioclavicular dislocations. Am I Sports Med 1987; 5: 264-72.

20 Stappaerts KH, Broos PLO, Mommens P, Debeer P. Surgical treatment of complete acromioclavicular separations. A review of 40 patients. Unfallchirurgie 1988; 91: 161-4. 